\title{
Research on Teaching Reform of Surveying in Architectural Colleges
}

\author{
Zhiwei Xie \\ Shenyang Jianzhu University \\ School of Transportation Engineering \\ Shenyang, China \\ zwxrs@sina.com
}

\author{
Xiaosong Qin \\ The Chinese University of Hong Kong \\ Institute of Space and Earth Information Science \\ Hong Kong, China \\ gxss7577@163.com
}

\author{
Lishuang Sun \\ Shenyang Jianzhu University \\ School of Transportation Engineering \\ Shenyang, China \\ 645695280@qq.com \\ Dayong Yang \\ Shenyang Jianzhu University \\ School of Transportation Engineering \\ Shenyang, China \\ ydy1120@163.com
}

\begin{abstract}
Aimed at the problem that teaching reform pace is far behind the actual engineering existing in surveying teaching in architectural colleges, this paper puts forward a new leading surveying teaching method to cultivate application-oriented talents by using new surveying technology and case application. This method takes reform measures in two sections, theory and practice of surveying teaching in architectural colleges. Theory teaching stresses that GPS and 3D laser theory teaching with architectural specialty characteristics should combine with surveying course. Practice teaching focuses on training students' practical ability so that they can apply surveying to architectural specialty area. Actual teaching effects show that this method can not only improve surveying course teaching quality in architectural colleges, but also can cultivate more qualified professional technical talents the society needs.
\end{abstract}

Keywords-surveying; teaching reform; new measurement techniques; practice

\section{INTRODUCTION}

Surveying is a very practical subject and it is required as a compulsory specialized basic course for non-geomatics major students in architectural colleges. The author and colleagues did some reform exploration in relative system and application from several surveying teaching experiments then get some achievement. The content of experimental teaching in the past was performed largely through experimental teaching syllabus and usually was not complete, could provide neither ultimate goal nor inspection measurement, emphasized too much on systematic introduction of textbook knowledge. In addition, training specifications were too theoretical, prescriptive and ideal. With the emergence and development of mid-rise buildings and high-rise buildings in urban construction, the emergence of complex geological and topographical conditions, the increasing of urban planning scale and requirement, a series of measurement instruments like ordinary optimal level and theodolite can't meet engineer's requirement and are replaced gradually by a series of new measurement instruments like

Education, teaching and research project of China Construction Education Association in 2017 (No. 2017077) digital level, laser theodolite, laser plummet apparatus and so on. However, these contents are only list as new instruments introduction or elective in surveying course, and the application technology is not in necessary experiment. Traditional plane and elevation control survey are being replaced by uniform three-dimensional control network, classic geometric leveling is being replaced by digital rangefinder trigonometric leveling. Many new technologies, new methods and new instruments have emerged.

By interviewing and researching some architectural colleges, the author finds a problem that pace of teaching reform is far more behind engineering practice and this problem has brought confusion to both graduates and engineering companies. The reason is that traditional teaching model has been difficult to adapt to actual needs of modern civil engineering production. Therefore, teaching content, teaching methods and practice teaching system need further design and reform. Efforts should make to train students' comprehensive practical ability and active thinking ability so that students can learn things that are more practical and meet the needs of social related talents [1].

\section{RESEARCh StATUS}

Surveying is a basic technical course in geomatics discipline, also a compulsory course for civil engineering, traffic engineering, surveying and mapping engineering and land management [2-3]. The main task is to develop students' ability in establishing engineering control network, surveying current topographic map, architecture, municipal, line, underground, industrial and other engineering survey, monitoring and forecasting construction buildings deformation, as well as relative data management and analysis, so that students can have a solid foundation and can engage in relative projects and research directly after graduating. Based on synthesizing domestic undergraduate surveying textbook content and combined some colleges' surveying syllabus, the 
author finds that teaching content of surveying course is mainly organized by each chapter system, such as surveying summary, leveling surveying, angle surveying, distance surveying, surveying errors, control surveying, topographic surveying and engineering surveying. Field surveying - indoor data processing - final surveying achievement becomes the teaching backbone. Leveling surveying, angle surveying and distance surveying constitute a parallel branch of surveying instrument operation. The main problem of this content system is that mapping process becomes the backbone, but basic surveying part in main backbone and construction application part at the end of backbone are weaken. Although students can use measurement instruments to collect coordinate data after completing courses, they lack deep understanding of some basic concepts, and they are unconscious of using collected data to serve for later specialized courses. This isolates the organic connections between specialized courses, also makes they can't effectively use surveying knowledge and to solve problems they meet in subsequent courses. The main reason for this contradiction is that non-geomatics major requires surveying skills in different level. Usually geomatics professionals are responsible for the preparation and formulation of the existing surveying textbooks and syllabus, but this process lacks non-geomatics professionals' participation [4]. Therefore, teaching content can't reflect the demands of various majors, only focusing on its generality but overlooking its specialty direction.

In non-geomatics majors' teaching in architectural colleges, how to tightly combine current engineering surveying technical requirement with practice application, at the same time actually highlight surveying professional characteristics and optimize the connections between courses is worth thinking and discussion. This paper uses surveying as example to discuss the difference of teaching content in architectural colleges' nongeomatics major and then build a teaching model, which is suitable for interdisciplinary development and integration based on this discussion.

\section{NeW TECHNOLOGY DEVELOPMENT GUIDES THE TEACHING REFORM}

\section{A. New Technology Development Guides the Teaching Reform in Theoretical Content}

With the development of new geomatics technology, surveying work methods and means have changed. Therefore, teaching process must reflect changes in surveying work bring by new technology, such as GPS, 3D laser scanner and InSAR, the following is illustrated with GPS [6].

GPS positioning technology has applied to all areas of national economy since it appeared in 1980s and continuous development. For surveying workers, GPS positioning system has been used in geodesy, crust movement monitoring, building engineering monitoring network, a variety of engineering measurements and so on [5].

The application characteristics of GPS in engineering are as followed:

- Building engineering control network. Usually use carrier phase static differential technology to achieve millimeter-level accuracy. Application of GPS technology in road exploration control network, construction control network, tunnel engineering control network and in many other aspects has significant advantages. Road surveying and construction control network has narrow horizontal and long vertical characteristics. Plans using traditional triangular chain and traverse measurement should be divided in several parts and then implemented for avoiding too large error accumulation. GPS technology can build triangular chain with long distance GPS point because it doesn't need point intervisibility and can maintain the consistency of long distance line coordinates control.

- Detail Surveying and Setting Out Using RTK. This can be applied to map topographic maps and cadastral maps, survey real estate boundary points and set out construction plane position. RTK technology needs only one person. Place GPS receiver at the feature point to be determined and enter the point's code. Terrain and ground feature points in a small area are measured and transmitted to a computer. Finally, a desired result map is formed by professional mapping software under proper artificial intervention. Use RTK technology can mark boundary points simply and conveniently.

- Deformation Monitoring Using GPS. In the monitoring of large-scale bridges, dams, the high-rise buildings and structures' foundation settlement, displacement and overall inclination and other conditions, one of conventional monitoring methods uses leveling surveying to monitor foundation settlement. If use triangulation surveying or angle intersection to monitor foundation settlement and overall inclination, the application of conventional monitoring methods not only requires long observation time and high labor intensity, but also difficult to achieve automatic monitoring because of objects' huge dimensions, complex monitoring environment and high monitoring technical requirement. GPS positioning technology has characteristics of high positioning precision. It doesn't need points intervisibility and can work in all-weather conditions.

It is obvious that with the rapid development of informationization, we need to optimize the surveying teaching content in non-geomatics surveying course teaching reform, and build a complete, scientific and reasonable engineering surveying course system. The same time in explanation of basic surveying and mapping knowledge, particularities of different engineering should be taken into consideration, also the application of measuring technology combined characteristics of bridge, water conservancy, industrial and civil architectural engineering with measuring content, from which can help student more proficient in the application of modern surveying and mapping technology. Make surveying and mapping technology become a main mean for researching the basis and application of relative subjects, also an important part constituting human knowledge and ability. 


\section{B. New Technology Development Guides the Teaching Reform in Practical Content}

Surveying is a very practical subject and it is required as a compulsory specialized basic course for civil engineering students, so measuring practice is an important part of the whole surveying teaching. By measuring practice, students can do a systematical practice with the knowledge they have learned and can help them understand, strengthen and broaden measuring theoretical knowledge.

Main problems in surveying practical teaching are about the following: outdated internship equipment have difficulties meeting the needs of new engineering application. Traditional internship instruments are mainly theodolite and plane table, but they can be hardly seen in current engineering companies and the most common is total station, also the application of GPS is more and more. So teaching equipment behind actual production becomes the primary problem for student can't adapt the society.

Current surveying practice content has difficulties adapting to the needs of specific civil engineering projects because of the deviation of internship content focus. Traditional mapping methods are gradually replaced by digital mapping and mapping work isn't civil engineering students' main work, such as their work in highway construction are mainly ground flattening, setting out for construction and deformation monitoring. Therefore, the focus of practice content is of great significance for cultivating students' expertise in different fields.

Current practice is single and general, and it is difficult to meet the needs of different professional technology requirement. In the view of traditional measurement mode shortcomings, the practice teaching reform is carried out from the following aspects under the driving force of the experimental condition improvement:

- Adjust the practice model framework to meet the social needs of students training requirements and establish a practice model based on new modern surveying and mapping equipment.

- Reform practice content. Turn students' practice focus to frequent-used surveying work according to respective professional field based on different major's surveying work content. For highway engineering, bridge engineering and civil engineering, choose relative typical measurement work and task as practice content focus respectively. Strengthen students' professional skills; make them fully aware of their own major's measurement technology requirement and operation points. Details are showed in TABLE I:

- Reform practice way. For the phenomenon that campus simulation has difficulties causing students to pay attention to the importance of measurement, advocate diversified practice ways and not limited to the campus, encourage teachers to lead students to participate actual construction project, try to combine practice with actual production, cultivate students' actual capability.
Through practice mode reform, students use total station, GPS and other new instruments as main tool in the practice and are able to use new surveying and mapping technology in engineering construction, also the difference between teaching and actual engineering is reduced. Different major students can master the key content of their own measurement work.

\section{THE IMPLEMENTATION OF TEACHING REFORM GUIDED BY THE DEVELOPMENT OF NEW TECHNOLOGY}

\section{A. Research Ideas and Methods}

Series of research work is based on a large number of investigations. Previous research has conducted in colleges with undergraduate geomatics major, like Shenyang Agricultural Science and Technology Liaoning, Northeastern University and so on. The researches focus mainly on teaching method, teaching effect, existing problems and other aspects of surveying course. Then get investigation data and a series of

TABLE I. PRACTICE CONTENT

\begin{tabular}{|c|c|c|c|}
\hline \multicolumn{4}{|c|}{ PRACTICE CONTENT } \\
\hline Specialty & Content 1 & Content 2 & Content 3 \\
\hline Enghway & $\begin{array}{c}\text { Route setting } \\
\text { out using total } \\
\text { station }\end{array}$ & $\begin{array}{c}\text { Data collection and } \\
\text { setting out using RTK } \\
\text { and GPS }\end{array}$ & $\begin{array}{c}\text { Leveling } \\
\text { surveying }\end{array}$ \\
\hline $\begin{array}{c}\text { Bridge } \\
\text { Engineering }\end{array}$ & $\begin{array}{c}\text { Pier setting out } \\
\text { using total } \\
\text { station }\end{array}$ & $\begin{array}{c}\text { Control surveying } \\
\text { using GPS and data } \\
\text { processing }\end{array}$ & $\begin{array}{c}\text { Elevation } \\
\text { transference }\end{array}$ \\
Civil & $\begin{array}{c}\text { Axis setting out } \\
\text { using total } \\
\text { station }\end{array}$ & $\begin{array}{c}\text { Control surveying } \\
\text { using GPS and } \\
\text { deformation } \\
\text { monitoring }\end{array}$ & $\begin{array}{c}\text { Ground } \\
\text { flattening }\end{array}$ \\
\hline
\end{tabular}

colleges experience as important reference for research. The next step, the research group will expand research scope, no than 20 colleges with undergraduate geomatics major will be investigated.

At the same time, questionnaire will be sent to nongeomatics students and discussion will be held to understand students' views on current surveying teaching situation, as well as needs and suggestions of the surveying teaching reform. On the other hand, views and suggestions from graduates and employers will be widely collected to understand the employers' requirement of students' ability. After summarizing all the information, a detailed practical surveying teaching reform plan will be formulated according to the results of all parties concerned. Technical route is shown in FIGURE I.

\section{B. Implementation Steps}

The first stage is course investigation, mainly about problems in surveying teaching content in non-geomatics majors in architectural colleges, on-campus students' views of surveying teaching content, method and teaching reform. Companies are also involved in this research, about what knowledge structure and skills students should master according to companies' specific need. The second stage is course research and implementation, key stage of the course. The main tasks are to determine what should be added and what should be deleted in surveying teaching content, choose 
cases for task-based teaching and heuristic teaching and determine surveying theoretical exam content and surveying internship content. The third stage is feedback and revision of the course. Examine, evaluate and revise surveying teaching plan based on the early implementation result.

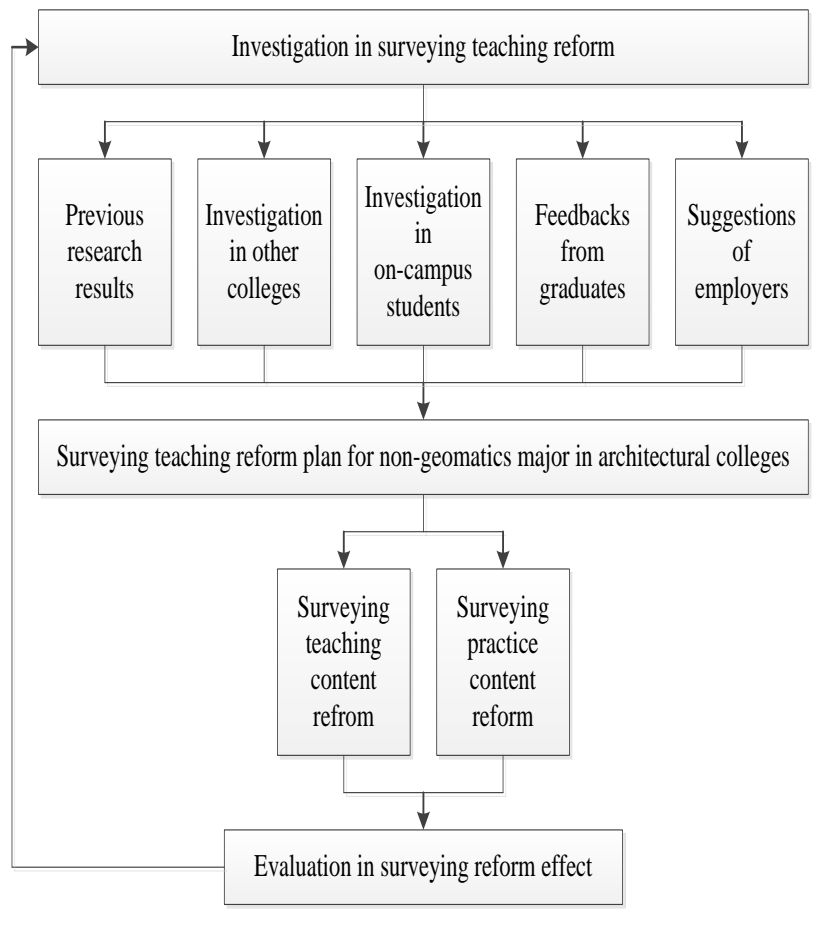

Fig. 1. Technical Route

Modify and optimize surveying teaching plan so that course reform fruit can be further improved based on the feedbacks from all aspects, like students, graduates and employers.

\section{CONCLUSION}

This paper focuses on surveying teaching reform in nongeomatics majors in architectural colleges, suggests that colleges should highlight the basic part of surveying and mapping, emphasize the application of measurement technology, enlarge the service scope of measurement technology, improve teaching conditions, then can raise students' interest in surveying and enhance students' ability to solve actual problems. At the same time, teachers should perfect teaching system, optimize connection between courses in combination with the emerging of new measurement theory, new instruments and new methods so that teaching quality can be gradually improved and more qualified professional technical talents the society needs can be cultivated.

\section{REFERENCES}

[1] Jian Xing, Zhang Zhenguo, Qiu Yinguo, Lu Lijiang and Wang Xuejuan. Exploration of Surveying Teaching Practice Reform of Non-Geomatics Major in Application-oriented Undergraduate Colleges[J]. Chuzhou, Anhui Agricultural Science Bulletin, 2015, (7): 154-155. (In Chinese)

[2] Gan Zhengru. Teaching Reform of Non-Geomatics Major's Surveying Course[J]. Ganzhou, Mine Surveying, 2016, (3): 141-145. (In Chinese)

[3] Wang Zumin. Discussion on Teaching Reform of Non-Geomatics Major's Surveying Course [J]. Suzhou, Journal of Zhangjiakou Vocational and Technical College, 2009, 22(1): 59-60. (In Chinese)

[4] Yu Kun,Wu Xuewei. A study of teaching reform for Surveying course in non-geomatics specialty[J]. Shanxie Achtecture,2015,42(8):234-236(In Chinese)

[5] Rycroft M J. Understanding GPS. Principles and Applications[J]. Journal of Atmospheric and Solar-Terrestrial Physics, 1996, 59(5): 598599.

[6] Gonzálezaguilera D, Gómezlahoz J, Sánchez J. A New Approach for Structural Monitoring of Large Dams with a Three-Dimensional Laser Scanner [J]. Sensors, 2008, 8(9): 5866-5883. 